\title{
The Effect of a Femoral Fracture Sustained before Skeletal Maturity on Bone Mineral Density: A Long-Term Follow-Up Study
}

\author{
J. A. Kettunen, ${ }^{1}$ S. Palmu, ${ }^{2,3}$ K. Tallroth, ${ }^{4}$ Y. Nietosvaara, ${ }^{2}$ and M. Lohman ${ }^{5}$ \\ ${ }^{1}$ Arcada University of Applied Sciences, Jan-Magnus Janssonin Aukio 1, 00550 Helsinki, Finland \\ ${ }^{2}$ Children's Hospital, Helsinki University Central Hospital, P.O. Box 281, 00029 Helsinki, Finland \\ ${ }^{3}$ Tampere Center for Child Health Research (TACC), University of Tampere and Tampere University Hospital, \\ Lääkärinkatu 1, 33014 Tampere, Finland \\ ${ }^{4}$ Orton Orthopaedic Hospital, Orton Foundation, P.O. Box 29, 00281 Helsinki, Finland \\ ${ }^{5}$ Department of Radiology, HUS Medical Imaging Center, Helsinki University Central Hospital and University of Helsinki, \\ P.O. Box 340, 00029 Helsinki, Finland
}

Correspondence should be addressed to J. A. Kettunen; jyrki.kettunen@arcada.fi

Received 28 June 2014; Revised 21 November 2014; Accepted 23 November 2014; Published 21 December 2014

Academic Editor: Werner Kolb

Copyright (C) 2014 J. A. Kettunen et al. This is an open access article distributed under the Creative Commons Attribution License, which permits unrestricted use, distribution, and reproduction in any medium, provided the original work is properly cited.

\begin{abstract}
Background and Purpose. The possible effect of pediatric femoral fractures on the bone mineral density (BMD) is largely unknown. We conducted a study to investigate BMD in adults who had sustained a femoral shaft fracture in childhood treated with skeletal traction. Materials and Methods. Forty-four adults, who had had a femoral fracture before skeletal maturity, were reexamined on average 21 (range 11.4) years after treatment. Our follow-up study included a questionnaire, a clinical examination, length and angle measurements of the lower extremities from follow-up radiographs, and a DEXA examination with regional BMD values obtained for both legs separately. Results. At follow-up femoral varus-valgus $(P=0.001)$ and ante-/recurvatum $(P=0.001)$ angles were slightly larger in the injured lower-limb compared to the contralateral limb. The mean BMD of the entire injured lower-limb was lower than that of the noninjured $\left(1.323 \mathrm{~g} / \mathrm{cm}^{2}\right.$ versus $\left.1.346 \mathrm{~g} / \mathrm{cm}^{2}, P=0.003\right)$. Duration of traction was the only factor in multiple linear regression analysis that was positively correlated with the BMD discrepancy between the injured and noninjured lower-limb explaining about $17 \%$ of its variation. Conclusion. The effect of a femoral fracture sustained during growth is small even in patients treated with traction.
\end{abstract}

\section{Introduction}

Decreased bone mineral density (BMD) has been diagnosed in adults as sequel of immobilisation and reduced weight bearing in the injured limb [1]. Henderson et al. [2] have reported a decreased BMD in proximal femur two years after tibial and femoral fractures in children that were immobilised for eight weeks or longer. Ferrari et al. [3] have found an association between a childhood fracture and low BMD in adulthood suggesting low peak bone mass and persistent bone fragility.

We studied long-term effects of pediatric femoral shaft fractures treated with skeletal traction on BMD.

\section{Materials and Methods}

Sixty-two pediatric patients ( $<16$ years old, all Scandinavian Caucasian) that had sustained a femoral fracture were treated with skeletal traction (in a hospital bed) in Aurora Hospital, Helsinki, during 1980-1989. The most common injury type was a motor-vehicle accident.

Patient files and primary radiographs of these patients were analysed. A questionnaire about subjective treatment results as well as an invitation to participate in a follow-up examination (mean 21, range 11.4, standard deviation (SD) 2.8 years) was mailed to all patients [4]. Fifty-two of the patients agreed to participate. They all gave written informed consent 
TABLE 1: Characteristics of patients at baseline and at follow-up.

\begin{tabular}{lcc}
\hline Characteristics & $\begin{array}{c}\text { At baseline } \\
(N=44)\end{array}$ & $\begin{array}{c}\text { At follow-up } \\
(N=44)\end{array}$ \\
\hline Age & $8.0(3.2)$ & $29.1(3.9)$ \\
$\quad$ Years; mean (SD) & $23-39$ \\
Minimum-maximum & $3-15$ & \\
Height & & $1.76(0.1)$ \\
m; mean (SD) & & $1.53-1.95$ \\
Minimum-maximum & & $74.8(15.7)$ \\
Weight & & $45-105$ \\
kg; mean (SD) & & $24.1(3.9)$ \\
Minimum-maximum & & $16-31$ \\
BMI & & \\
kg/m ${ }^{2}$; mean (SD) & & \\
Minimum-maximum & & \\
Fracture location & & \\
Proximal & 13 & \\
Distal & 11 & \\
Mid-shaft & 28 & \\
Treatment method & & \\
Traction & & \\
Tibial traction & & \\
Femoral traction & 34 & \\
\hline
\end{tabular}

${ }^{1}$ SD: standard deviation.

${ }^{2}$ BMI: Body Mass Index.

approved by the local Ethics Committee of the Helsinki University Central Hospital (approval identification number 68/E7/2002)

Forty-four patients (15 females, 29 males, mean age 29 years) attended the follow-up study including clinical examination, lower-limb radiographs, and DEXA examination. None of our patients was known to have any metabolic or other disease, neither as child nor as adult. Demographics data of the patients are seen in Table 1.

The radiographic examinations were conducted at the time of the follow-up and consisted of standing anteroposterior radiographs of both legs and standing lateral views of the femurs. The anteroposterior hip-to-ankle radiographs were obtained separately of both extremities. They were taken in fluoroscopy control at a distance of $1.5 \mathrm{~m}$ on analog films. For length measurements a long radio-opaque ruler was fixed to the leg. The images were evaluated for the length of the lowerlimbs and femurs in millimetres.

The mechanical axis of the entire leg was measured according to the method described by Hagstedt et al. [5]. In addition to the mechanical axis both femurs were analysed for angular deformity in two planes, that is, varus/valgus in the frontal view and ante-/recurvatum in the lateral view. For these assessments of the coronal and lateral curves lines through the midsection of the proximal and distal femoral diaphyses were drawn and measured with a manual goniometer.

DEXA examinations were performed using a narrow fanbeam Lunar Prodigy densitometer (GE Lunar Corporation,

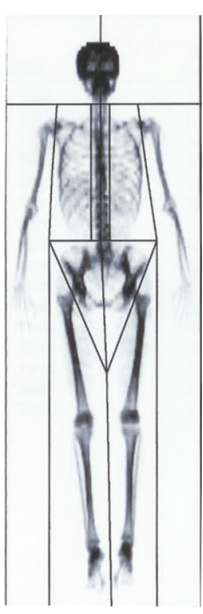

FIGURE 1: Whole body DEXA measurement, demonstrating measurement areas separately for each lower extremity.

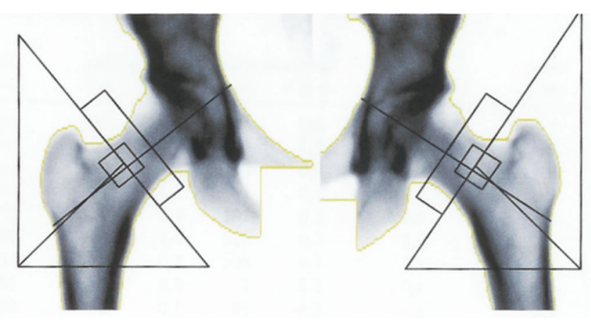

Figure 2: The areas for bone mass measurement for the right and left femoral neck.

Madison, WI, USA). To verify the stability of the DEXA system a control procedure of the scanner was performed weekly in addition to a daily calibration according to manufacturer's instructions.

The subjects were positioned in supine position on the scanning table with the body aligned with the midline of the scanning table. The legs were straight and strapped in slight internal rotation. The Lunar Prodigy software uses a series of complex algorithms to calculate BMD and bone mass in the total body and for different anatomical regions, in our study the legs and femoral necks (Figures 1 and 2). The results were measured and reported as kilograms for total body weight (BW) and BMD was measured in $\mathrm{g} / \mathrm{cm}^{2}$.

Bone density was separately measured in the lower legs (Figure 1) and in femoral neck (Figure 2). In previous studies from our institution with the same scanner the precision of total bone and extremity density measurements have shown excellent repeatability and are expressed as the coefficient of variation 1,0\% for total body [6] and 1,6\% for the lower extremity [7]. The precision is consistent with the literature $[8,9]$.

Two senior musculoskeletal radiologists made all the radiographic (M. Lohman) and DEXA measurements (K. Tallroth) independently of each other and blinded regarding previous readings.

The statistical analysis was done with Statistical Package for the Social Sciences 21.0 (Norusis/SPSS, Inc., Chicago, IL). 
TABLE 2: Lower-limb length, femur length, and lower-limb angular deformities at follow-up radiographic evaluation among patients with a childhood femoral fracture.

\begin{tabular}{|c|c|c|c|c|}
\hline Characteristics & Noninjured mean $(\mathrm{SD})^{1}$ & Injured mean $(\mathrm{SD})^{1}$ & Noninjured-injured mean $(95 \% \mathrm{CI})^{2}$ & $P$ value \\
\hline Lower-limb length, $\mathrm{cm}$ & $84.8(5.9)$ & $84.5(6.2)$ & $0.3(-0.2$ to 0.8$)$ & 0.287 \\
\hline Femur length, $\mathrm{cm}$ & $47.5(4.9)$ & $46.9(3.7)$ & $0.7(-0.4$ to 1.7$)$ & 0.224 \\
\hline Mechanical axis, degrees & $2.1(1.9)$ & $3.5(2.8)$ & $-1.4(-2.3$ to -0.6$)$ & 0.001 \\
\hline \multicolumn{5}{|l|}{ Femoral angulation } \\
\hline Ante-/recurvatum, degrees & $8.3(2.3)$ & $11.6(6.4)$ & $-3.3(-5.1$ to -1.4$)$ & 0.001 \\
\hline Varus-valgus, degrees & $1.2(2.0)$ & $3.4(3.6)$ & $-2.2(-3.4$ to -1.0$)$ & 0.001 \\
\hline
\end{tabular}

${ }^{1}$ SD: standard deviation.

${ }^{2} \mathrm{CI}$ : confidence interval.

Paired samples or independent samples $t$-test was used to test differences between the lower-limbs among variables with normal distribution. Correspondingly, Wilcoxon signed rank test or Mann-Whitney $U$ test was used among not normally distributed variables. Pearson's product moment correlation coefficient or Spearman's rho was used to investigate the relationship between different factors and BMD. Multiple linear regression analysis was used to study the determinants of the noninjured minus injured lower-limb BMD difference.

To evaluate the factors associated with the lower-limb BMD difference, the following factors were entered into a stepwise multiple regression analysis:

(i) gender,

(ii) age at injury,

(iii) traction time,

(iv) height,

(v) weight,

(vi) BMI,

(vii) follow-up time,

(viii) noninjured minus injured lower-limb length difference,

(ix) noninjured minus injured femur length difference,

(x) noninjured minus injured thigh circumference difference noninjured minus injured lower-limbs mechanical axis difference,

(xi) noninjured minus injured lower-limbs femoral varusvalgus difference,

(xii) noninjured minus injured lower-limbs femoral ante/recurvatum difference.

\section{Results}

Mean duration of skeletal traction was 39.6 days (range 74, SD 15.8). Significant differences in leg lengths were not found (Table 2). Mean mechanical axis in both frontal and sagittal planes was slightly larger in the injured lower-limb compared to the noninjured contralateral limb (Table 2).

Whole body BMD was within normal limits in all patients according to the manufacturer's reference values. Mean BMD of the entire injured lower-limb was lower than that of the noninjured lower-limb $\left(1.323 \mathrm{~g} / \mathrm{cm}^{2}\right.$ versus $1.347 \mathrm{~g} / \mathrm{cm}^{2}$,
$P=0.003)$. BMD of the femoral neck of the injured lower-limb did not differ from the limb without an injury (mean $0.998 \mathrm{~g} / \mathrm{cm}^{2}$ versus $0.995 \mathrm{~g} / \mathrm{cm}^{2}, P=0.806$ ). BMD difference between the injured and the noninjured limb was statistically significant in male patients (mean $1.403 \mathrm{~g} / \mathrm{cm}^{2}$ versus $1.380 \mathrm{~g} / \mathrm{cm}^{2}, P=0.023$ ), but not in female patients (mean $1.245 \mathrm{~g} / \mathrm{cm}^{2}$ versus $1.227 \mathrm{~g} / \mathrm{cm}^{2}, P=0.203$ ).

The only factor that was associated with the lower-limbs BMD difference was the duration of traction explaining about $17 \%$ of its variation.

\section{Discussion}

In the 1980s most pediatric femoral fractures in Finland were treated without internal fixation, which allowed us to perform DEXA measurements on these patients without disturbing fixation devices such as metal plates or nails. The BMD was not evaluated before the fracture took place, which is obviously a limitation of our study. However, the mean follow-up time after the fracture was longer than in most of the previous studies.

Femoral fractures sustained before skeletal maturity have been reported to reduce the injured femur's BMD distal to the fracture site $[1,10]$, lower BMD values than in the noninjured extremity have been registered in the injured extremity 11 years after tibial shaft fractures [11], and girls have been reported to have a decreased body bone mineral content four years after a distal forearm fracture [12]. Our findings are in line with these earlier studies although we found that BMD of the injured lower extremity was only slightly lower compared (mean 2\%) to the noninjured lower extremity. Furthermore, we did not find a decreased BMD proximal to the fracture. Malignment of the femur in neither frontal nor sagittal plane correlated with BMD in this study. No correlation was found between the mechanical axis of the lower extremity and the BMD. This is most likely explained by the fact that only few patients in our study with malunion had permanent deformity that is regarded unsatisfactory according to clinical guidelines [13].

Nikander et al. [14] concluded that exercise can significantly enhance bone strength at loaded sites in children. Leppälä and coworkers [10] found a positive correlation between muscle strength and bone density of the tibia in patients that had been rehabilitated from a tibial fracture. We did not collect data of physical activity nor test muscle 
function of our patients. No difference was however found in femoral circumferences suggesting recovery of muscle function of the injured leg.

Pediatric femoral fractures treated with several weeks long skeletal traction in bed do not lead to clinically significant decrease of BMD of the lower extremity in adulthood.

\section{Conflict of Interests}

The authors declare that there is no conflict of interests regarding the publication of this paper.

\section{References}

[1] B. E. Nilsson and N. E. Westlin, "Restoration of bone mass after fracture of the lower limb in children," Acta Orthopaedica Scandinavica, vol. 42, no. 1, pp. 78-81, 1971.

[2] R. C. Henderson, G. J. Kemp, and E. R. Campion, "Residual bone-mineral density and muscle strength after fractures of the tibia or femur in children," Journal of Bone and Joint SurgerySeries A, vol. 74, no. 2, pp. 211-218, 1992.

[3] S. L. Ferrari, T. Chevalley, J.-P. Bonjour, and R. Rizzoli, "Childhood fractures are associated with decreased bone mass gain during puberty: an early marker of persistent bone fragility?" Journal of Bone and Mineral Research, vol. 21, no. 4, pp. 501-507, 2006.

[4] S. A. Palmu, M. Lohman, R. T. Paukku, J. I. Peltonen, and Y. Nietosvaara, "Childhood femoral fracture can lead to premature knee-joint arthritis," Acta Orthopaedica, vol. 84, pp. 71-75, 2013.

[5] B. Hagstedt, O. Norman, T. H. Olsson, and B. Tjornstrand, "Technical accuracy in high tibial osteotomy for gonarthrosis," Acta Orthopaedica Scandinavica, vol. 51, no. 6, pp. 963-970, 1980.

[6] V. M. Mattila, K. Tallroth, M. Marttinen, O. Ohrankammen, and H. Pihlajamaki, "DEXA body composition changes among 140 conscripts," International Journal of Sports Medicine, vol. 30, no. 5, pp. 348-353, 2009.

[7] M. Lohman, K. Tallroth, J. A. Kettunen, and M. T. Marttinen, "Reproducibility of dual-energy $\mathrm{x}$-ray absorptiometry total and regional body composition measurements using different scanning positions and definitions of regions," Metabolism: Clinical and Experimental, vol. 58, no. 11, pp. 1663-1668, 2009.

[8] G. M. Kiebzak, L. J. Leamy, L. M. Pierson, R. H. Nord, and Z. Y. Zhang, "Measurement precision of body composition variables using the Lunar DPX-L densitometer," Journal of Clinical Densitometry, vol. 3, no. 1, pp. 35-41, 2000.

[9] G. M. Chan, "Performance of dual-energy x-ray absorptiometry in evaluating bone, lean body mass, and fat in pediatric subjects," Journal of Bone and Mineral Research, vol. 7, no. 4, pp. 369-374, 1992.

[10] J. Leppälä, P. Kannus, S. Niemi, H. Sievänen, I. Vuori, and M. Järvinen, "An early-life femoral shaft fracture and bone mineral density at adulthood," Osteoporosis International, vol. 10, no. 4, pp. 337-342, 1999.

[11] J. Leppälä, P. Kannus, H. Sievänen, I. Vuori, and M. Järvinen, "A tibial shaft fracture sustained in childhood or adolescence does not c to interfere with attainment of peak bone density," Journal of Bone and Mineral Research, vol. 14, no. 6, pp. 988-993, 1999.

[12] I. E. Jones, R. W. Taylor, S. M. Williams, P. J. Manning, and A. Goulding, "Four-year gain in bone mineral in girls with and without past forearm fractures: a DXA study," Journal of Bone and Mineral Research, vol. 17, no. 6, pp. 1065-1072, 2002.

[13] J. M. Flynn and D. L. Skaggs, "Femoral shaft fractures," in Rockwood and Wilkins' Fractures in Children, Beaty and Kasser, Eds., chapter 22, pp. 797-841, Lippincott Williams \& Wilkins, Philadelphia, Pa, USA, 7th edition.

[14] R. Nikander, H. Sievänen, A. Heinonen, R. M. Daly, K. UusiRasi, and P. Kannus, "Targeted exercise against osteoporosis: a systematic review and meta-analysis for optimising bone strength throughout life," BMC Medicine, vol. 8, article 47, 2010. 


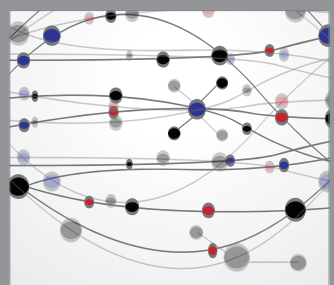

The Scientific World Journal
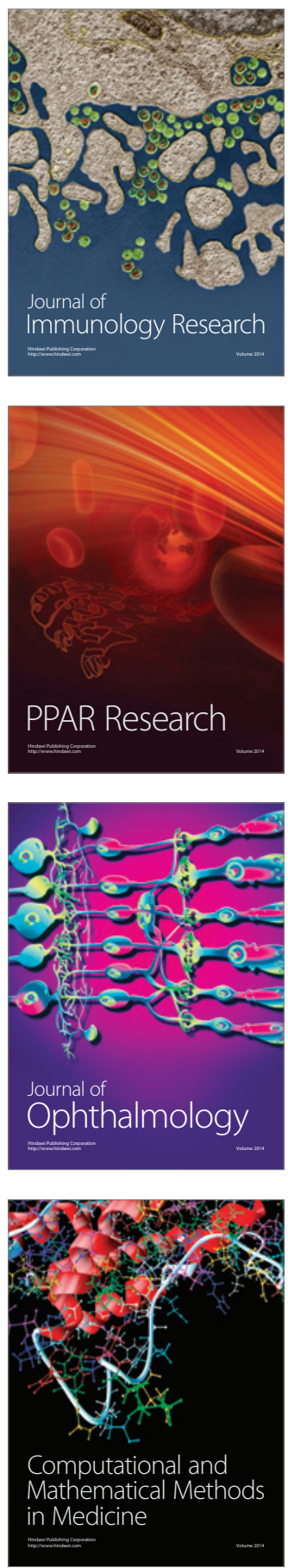

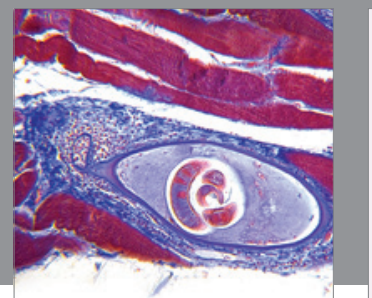

Gastroenterology

Research and Practice
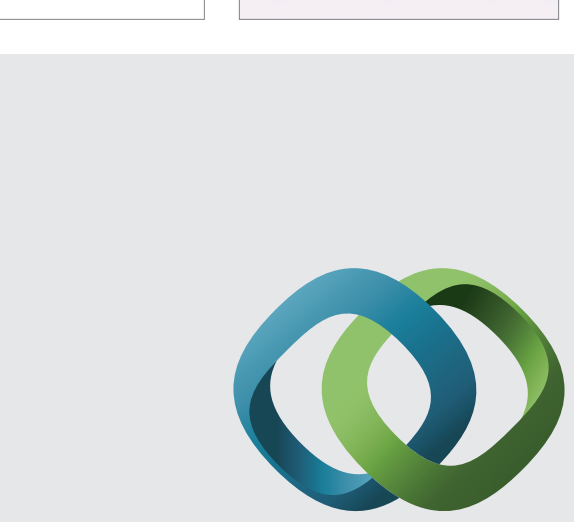

\section{Hindawi}

Submit your manuscripts at

http://www.hindawi.com
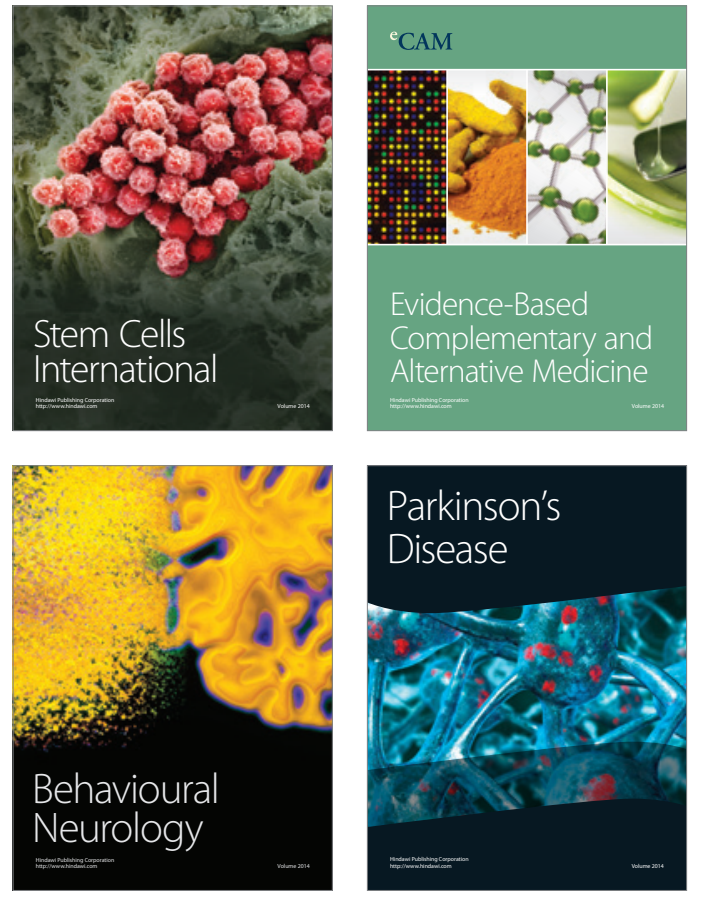
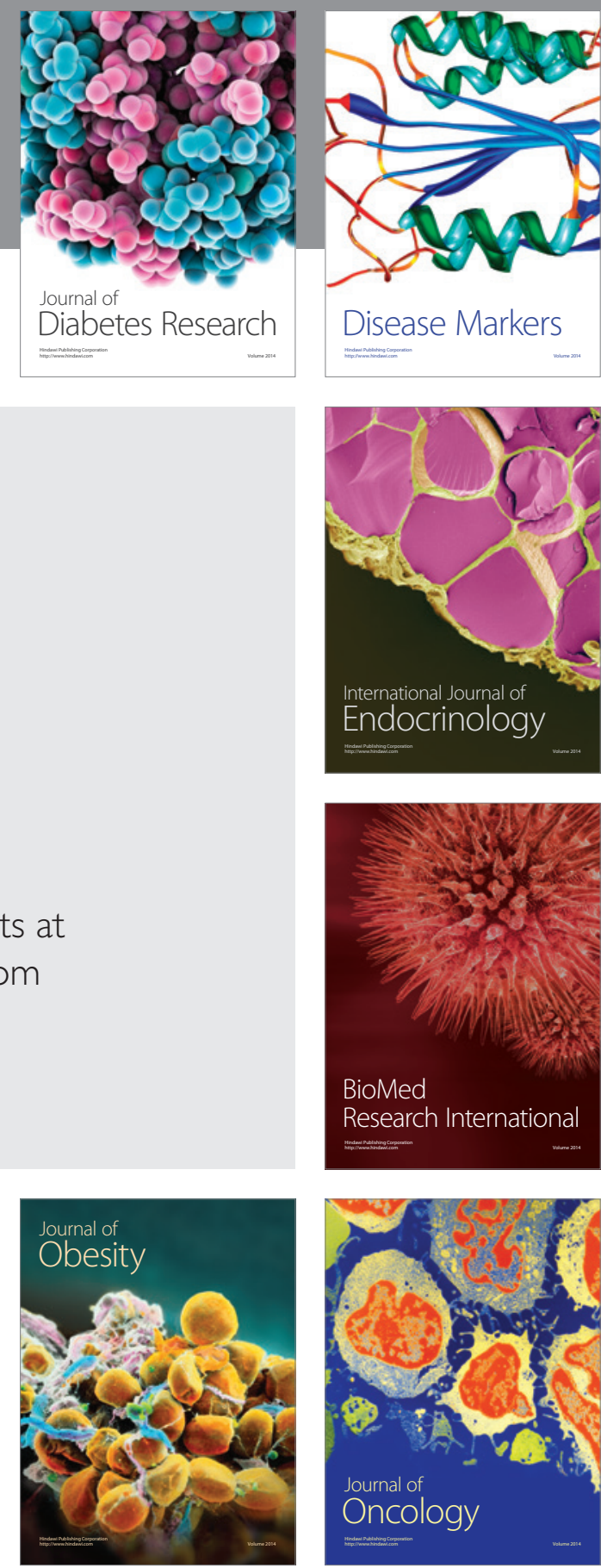

Disease Markers
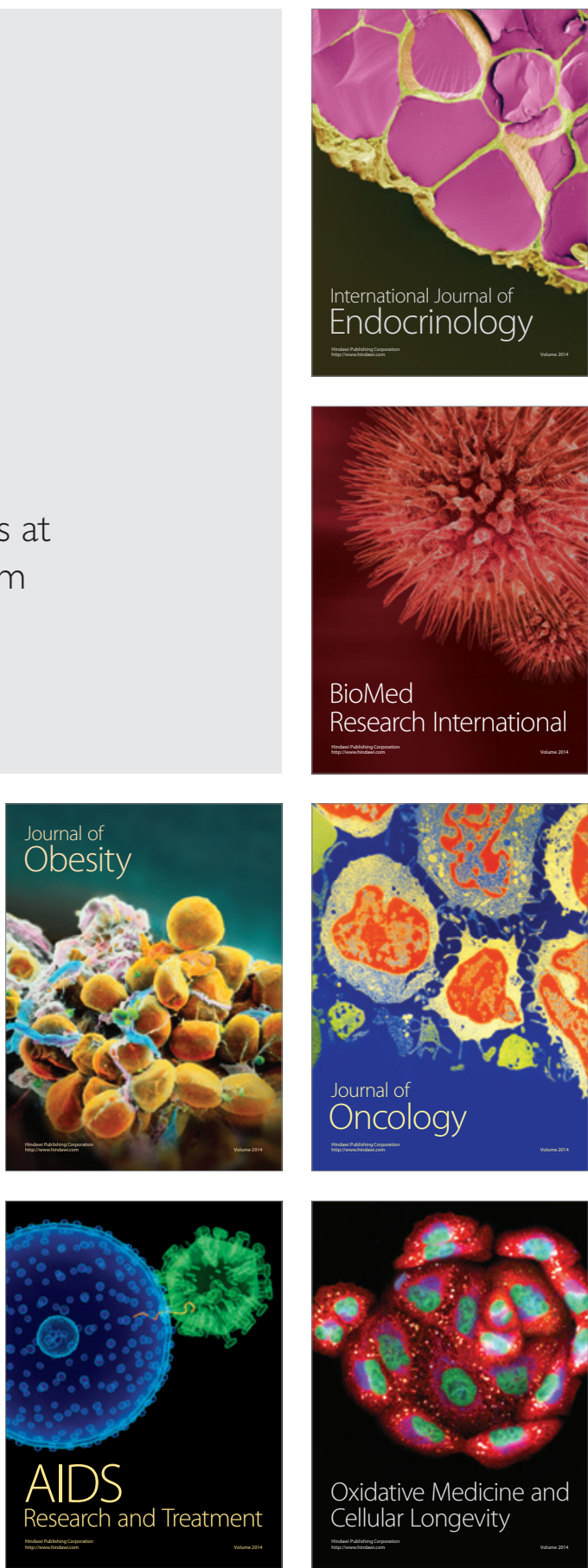